\title{
O desvio de um viajante: a recepção da obra de José de Alencar em Portugal ${ }^{1}$
}

\section{Marcelo Peloggio*}

Resumo: O presente artigo tem por objetivo mostrar a recepção da obra de José de Alencar pela crítica portuguesa dos séculos XIX e XX. Ou seja: procura formar um painel descritivo do pensamento luso a partir da idéia mesma de uma autonomia literária e "lingüística" motivada pelo romancista brasileiro.

\begin{abstract}
This article aims to demonstrate the reception of José de Alencar's works by the Portuguese critics in the XIX and XX centuries. In other words, this article seeks to set a descriptive portrait of the Lusitanian thought from the same idea of a literary and "linguistic" autonomy motivated by the Brazilian novelist.
\end{abstract}

Keywords: José de Alencar; Portuguese Critics; Brazilian Literature.

Pouco se disse acerca da recepção da obra de José de Alencar em Portugal. E muito do que sabemos a esse respeito, liga-se às polêmicas sobre a maneira de se escrever o português. Tomando-se por esse ângulo a questão, percebe-se que, no geral, a obra alencarina saiu prejudicada, pois a acolhida lusitana terá em Pinheiro Chagas seu nome mais expressivo.

Isso porque a crítica de Pinheiro Chagas, além de superficial, inaugurou, ao que tudo indica, a moda de se pôr defeito na prosa lírica do autor de $O$ Guarani, vista a partir de então como desleixada e incorreta. Também abriu espaço para outro bordão que ecoa até hoje: o de que Alencar é menos original do que mostra ser, já que suas obras não passam de reflexos pálidos das de autores consagrados, como Walter Scott, Fenimore Copper e Alexandre Herculano.

Ora, se Pinheiro Chagas constitui o principal nome da recepção lusitana, é de se convir que careceu José de Alencar, também em Portugal, de uma crítica leal, justa e independente.

Em Pinheiro Chagas, é clara a ambição de se fundar a literatura brasileira, numa espécie de disputa por essa primazia; tanto é que, após criticar a "insubordinação gramatical"

\footnotetext{
${ }^{1}$ Este artigo é fruto de uma bolsa de doutorado sanduíche, cuja pesquisa, realizada em Portugal, desenvolveu-se entre os meses de novembro de 2004 e abril de 2005 sob o patrocínio da CAPES.

* Marcelo Peloggio é Doutor em Letras pela Universidade Federal Fluminense.
} 
de Iracema (1865), o autor traz igualmente a lume obra de caráter histórico-indiano: A Virgem Guaraciaba (1866).

Em sua primeira crítica à Iracema, no Anuário do Arquivo Pitoresco (1866), Pinheiro Chagas expõe o teor do que será mais largamente desenvolvido em seus Novos Ensaios Críticos (1868): numa palavra, Iracema ainda não designa, com total plenitude, a nacionalidade brasileira:

Iracema é uma lenda do Ceará, dos tempos da descoberta, e revela uma tendência louvável para dar autonomia à literatura brasileira. O sr. J. de Alencar procurou a inspiração do seu poemazinho em prosa nas tradições da sua terra natal, na voz das suas florestas, no esplendor das suas paisagens, e foi bastante feliz para que possamos agoirar um grande sucesso ao trabalho mais desenvolvido que nos promete sobre assuntos idênticos (CHAGAS, 1866, p. 198).

E há de sugerir, por fim, maior asseio no estilo - o que representa, de modo velado, uma crítica à tentativa de autonomia cultural, que passa a ser reivindicada também na forma de expressão:

Bem sei que a pompa é necessária nestes quadros, que tem de copiar uma natureza gongórica (permitam-me a expressão) nestes dramas em que os atores falam a linguagem colorida e imaginosa dos povos selvagens, e especialmente dos povos selvagens da América; mas o bom senso do sr. Alencar melhor lhe indicará, do que eu o poderia fazer, o modo como há de arrancar as plantas parasitas, sem que se lhe enfeze o tronco, nem lhe agorente a seiva da sua formosa árvore (CHAGAS, 1866, p. 198).

Em os Novos Ensaios Críticos, Pinheiro Chagas (1868, p. 212) diz não haver uma literatura nacional na "antiga colônia", de vez que a primeira deve refletir "o caráter de um povo, que dá vida às suas tradições e crenças”. Assim, mostra ter ignorado por completo as realizações alencarinas, no sentido mesmo de fundação da literatura brasileira: antes mesmo de Iracema, já recebia a designação de "romance nacional" O Guarani (1857) e As Minas de Prata (1865-6).

Mas do pouco amealhado, é de se perceber que a obra de José de Alencar conquistou a estima de boa parte da crítica lusitana, reconhecendo no autor de Lucíola um artista de grande estro e engenho.

De todo modo, houve o entendimento de que seu trabalho merecia destaque, por conta de seu talento e como expressão singular e máxima da literatura brasileira, como bem revelam as linhas, de 1866, de Inocêncio Francisco da Silva: "Talento ilustre, hoje na razão da virilidade [...], por ele já abrilhantada em muitas e variadas publicações de mérito inquestionável” (FRANCISCO DA SILVA, 1866, p. 244). A notável erudição de Inocêncio (1866, p. 245) aponta ainda para um estudo de Alencar sobre a alimentação no Brasil; e seu Dicionário Bibliográfico Português, sob a direção de Brito Aranha, traz levantamento completo da produção do autor brasileiro (FRANCISCO DA SILVA, 1885, p. 128-134). 
No mesmo ano de 1866, Alencar é destacado por Romeo Júnior (1866, p. 6-7), que o localiza entre os mais ilustres da inteligência brasileira, ao lado de Monte Alverne, Gonçalves Dias, Macedo, Casimiro de Abreu, Álvares de Azevedo e Machado de Assis. Em 1872, Rangel de Lima (1872, p. 95) noticia carta de Alencar para o escritor brasileiro Juvenal Galeno.

Dos autores portugueses de maior nomeada, apenas Ramalho Ortigão ocupa-se de José de Alencar: por ocasião da morte do romancista. As belas palavras de As Farpas simbolizam, talvez, o reconhecimento tardio no elogio repassado de tristeza. Diz que "a humanidade pagou à morte um pesado tributo" (ORTIGÃO, 1887, p. 207); e, a modo de entronizar o nome do criador de Iracema, põe-no ao lado de Soromenho, Raspail, Courbet e Vítor Emanuel, que desaparecem no período. Sendo assim, diz o publicista luso:

\begin{abstract}
A morte de José de Alencar, o autor do Guarani e de Lucíola, representa uma das maiores perdas para a literatura brasileira, tão notável nos últimos tempos pela cooperação dos seus poetas e dos seus pensadores.

$[\ldots]$

Ele, que alcançara um dos mais luminosos lugares entre os homens mais célebres e mais prestigiosos do seu tempo, saíra do esgoto da cidade, procedera da roda dos expostos.

Esse enjeitado era a personalização mais gloriosa da soberania do trabalho, afirmando ele mesmo o seu direito, desembainhando no trono da arte a sua larga espada de justiça, vestindo a túnica e a dalmática azul, calçando as esporas de ouro nos coturnos bordados de lises, e fazendo-se ungir e sagrar pelas multidões como os antigos eleitos do Senhor. E era a ele, como a todo o artista vitorioso e triunfante, que se deveria dizer como Samuel ao rei Saul: "Deus te elegeu para reinar sobre a sua herança e para livrar os povos das mãos dos seus inimigos" (1887, p. 215-216).
\end{abstract}

E mesmo em Silva Pinto, cujo preconceito aos brasileiros faz propagar juízos destabocados, é possível ler: "Com a morte de José de Alencar extinguiu-se o veio opulento do romance nacional, com o poderoso cunho característico do independente criador" (PINTO, 1879, p. 155).

De fato, com sua morte, reconhecida será a irreparável perda; por causa dela - como acontece aos de maior gênio -, seu nome pode resplandecer e, de permeio, a nossa literatura, “tão notável [...] pela cooperação dos seus poetas e dos seus pensadores" (ORTIGÃO, 1887, p. 215).

Em 1876, esteve José de Alencar na capital dos lusos, quando de viagem à Europa por aconselhamento médico, uma vez que os sintomas da tuberculose se complicavam. Conforme Araripe Júnior, houve, em Lisboa, a abstenção de o receberem, e "um desagradável encontro de desafeições literárias" (ARARIPE JÚNIOR, 1958, p. 237); em outras palavras, “o romancista não se sentiu bem, evitando contato com os elementos que [...] o haviam atacado" (BROCA, 1955, p. 36). Por isso 
é freqüente dizer-se não haver sido ele bem acolhido em Lisboa. Possíveis ressentimentos contra o preconizador da língua brasileira. É admissível ter sido menos homenageado do que esperava. Contudo, a julgar pelo amplo noticiário dos jornais, receberam-no com elogios e honras de confrade eminente (VIANA FILHO, 1981, p. 313).

Pinheiro Chagas, através do jornal Diário da Manhã, registra a chegada de Alencar com "simpatia e admiração" - tributo que ainda se pode prestar a um homem já perto do fim:

$\mathrm{O}$ sr. Alencar é talvez o romancista que tem sabido imprimir melhor às suas obras o cunho americano.

Os selvagens que figuram muitas vezes nos seus romances vivem, falam a sua linguagem colorida e pitoresca, desenham bem a sua pensativa figura no fundo maravilhoso, na decoração esplêndida da portentosa natureza brasileira. Não são cópias dos selvagens de Cooper, ainda que têm com eles o natural parentesco dos filhos das selvas, ainda não modificados pelo contato da civilização, mas sente-se que vivem debaixo dum sol de fogo, que lhes incende a fantasia e lhes inspira uma linguagem que reflete nas suas imagens, como o colibri nas asas variegadas, as múltiplas cores do prisma.

$[\ldots]$

Debaixo da sua pena as florestas virgens têm vida, voz e cor, enlaçam-se os cipós nas árvores gigantes, resplendem as bromélias escarlates, expande a bananeira as suas largas folhas e as aves brasileiras, diamantes alados, voejam na ramaria despertando os ecos com a sua voz melodiosa. A Iracema é uma miniatura verdadeiramente adorável, mas o Guarani é um quadro que bastaria por si só para imortalizar o autor (CHAGAS, 1876a, $1^{\text {a }}$ página).

Busca aparar as arestas do ressentimento criado com o panfleto de 68. De tal modo que, no número seguinte, informa as casas em que podem ser encontradas as obras de "um dos mais notáveis escritores brasileiros" (CHAGAS, 1876a, $1^{\text {a }}$ página): "Na antiga livraria de Bertrand, aos Mártires, e na Internacional de E. Chardron, no Porto, encontra-se a maior parte de suas obras, e no tomo V do Dicionário Bibliográfico de Inocêncio da Silva, e no tomo IX do Arquivo Pitoresco noticia sobre sua vida” (CHAGAS, 1876b, $1^{\text {a }}$ página).

A folha Democracia também lhe dedica algumas palavras de reconhecimento - o que mostra o empenho da imprensa lisboeta para disseminar uma idéia de profunda cordialidade ante a presença de Alencar em Portugal: “A América não lhe poderá negar o título de benemérito que ele granjeou com a pena e com a palavra, e nós, que nos honramos hoje com a sua visita, saudamos com jubilo este ilustre cidadão” (Democracia, 1876, $1^{\text {a }}$ página).

Eduardo Coelho, em o Diário de Notícias, sepulta as desavenças em torno da língua; há de derribar, em algumas linhas, o conceito atormentador de "escritor incorreto e descuidado" (ALENCAR, 1951, p. 190), e que acompanhou José de Alencar até o dia das exéquias:

Poeta, romancista, dramaturgo, orador, legislador e homem de Estado, José de Alencar é um vulto de superior estatura, ao qual devem prestar-se as homenagens a que o talento tem jus. Nós saudamo-lo com tanto mais respeito e afeto quanto é certo que o consideramos três vezes ligado a nós, embora se ache no mais levantado elo dessa cadeia indissolúvel - pela confraternidade literária, pelo sangue e tradições, pela língua que fala, e em que tão brilhantemente escreve (COELHO, 1876a, $1^{\text {a }}$ página). 
Registra, igualmente, a saída de Alencar para o Rio, insistindo em realçar-lhe as qualidades de escritor apurado, a ponto de contribuir para o enriquecimento geral da língua portuguesa:

Parte hoje para o Rio de Janeiro, com sua esposa e filhos, depois de uma viagem de oito meses pela Europa, um dos quais foi dedicado a Lisboa, o sr. conselheiro José de Alencar, distinto escritor e homem de Estado brasileiro, que tanto lustre tem dado com seus escritos e discurso à língua de Camões e Vieira (COELHO, 1876b, $1^{\text {a }}$ página).

Alencar teria conhecido, entre os lusos, um admirador fervoroso e ilustre, o Visconde de Benalcanfor. Sabe-se que este lhe enviou de Cascais uma de suas obras, De Lisboa ao Cairo, e depois mais outra, Na Itália; em carta, exalta José de Alencar como "uma das glórias da literatura e da tribuna brasileiras" (Apud MENESES, 1967, p. 129). Como a refutar a qualificação errônea de "antilusitano", o autor de $O$ Guarani responde:

Foi para mim uma fortuna e honra, ao entrar esta bela e laureada capital de Portugal, receber a saudação amiga de uma das glórias mais legítimas da terra ilustre, a que me prende a fraternidade da língua, da raça e das tradições que nos são comuns, como comuns devem ser nossos esforços para restituir a essa família da humanidade os seus brilhantes destinos (Apud MENESES, 1967, p. 81).

Também presenteia Benalcanfor: com "um discurso, que [...] mostrará o homem político", e um romance, “o último publicado” (Apud MENESES, 1967, p. 82) provavelmente $O$ Sertanejo, lançado em 1875.

E foi assim que o autor brasileiro e os lusos freqüentaram-se, fosse por meio da palavra escrita, ou pessoalmente, como o fizeram o próprio Benalcanfor e Brito Aranha (FRANCISCO DA SILVA, 1885, p. 130)², que o visitaram em Lisboa.

Ainda que tenha sido modesta a recepção lusitana, foi sem dúvida significativa no tocante a um seguinte aspecto: a literatura brasileira teve seu reconhecimento mediante os esforços continuados de José de Alencar. Morre o homem, mas fica-lhe o legado superior: daquele "que se propôs criar uma língua literária de cunho brasileiro" (COELHO, 1981, p. x).

Força é dizer que ultrapassará, e muito, o século XIX; pois quem haverá de ganhá-lo para si é a posteridade: não será considerado apenas como o reformador de nossa língua literária, mas também como aquele que trabalhou para edificar o "pensamento brasileiro".

No limiar do século, ganha as páginas de Sousa Cordeiro (1898, p. v-vi), que, em pequeno mas admirável estudo biográfico e artístico, lembra ser Alencar "uma das glórias da grande nação brasileira"; vai celebrar-lhe igualmente "as altas faculdades mentais"; e seu estilo é de uma "linguagem de inexcedível magia". Chama-o de "o grande brasileiro", "o imortal autor de Iracema" (SOUSA CORDEIRO, 1898, p. xxviii e xxxii).

\footnotetext{
${ }^{2}$ Eis o testemunho de Brito Aranha: "Conheci-o e visitei-o em Lisboa. A enfermidade que o dominava, causando-lhe graves estragos, imprimira-lhe nas faces os sinais de uma cruel melancolia".
} 
Entretanto, o que mais conta aí, é a tentativa de se relativizar a polêmica em torno do problema da linguagem, não pendendo, desse modo, para nenhuma das facções envolvidas. Diz Sousa Cordeiro:

Questionou-se muito acerca da linguagem de que ele usava, pretendendo alguns ver nela incorreções e desmandos, e proclamando-o outros um inovador e o verdadeiro precursor de uma futura linguagem propriamente brasileira.

Nem uma nem outra coisa. As notadas incorreções não passam de insignificantes modismos comuns a quase todos os escritores brasileiros, e alguns neologismos de sua lavra. Mas tudo isso é também muito secundário para autorizar o papel de reformador da linguagem que lhe distribuíram, e que ele mesmo supôs ter representado (SOUSA CORDEIRO, 1898, p. xxiixxiii).

Por fim, a exemplo de Eduardo Coelho, também reabilita José de Alencar da famosa pecha de escritor incorreto, ressaltando-lhe os méritos de grande autor com o seguinte juízo: "Quem ler despreocupadamente os livros de Alencar, fica bem convencido de que ele (à parte a colocação dos pronomes e a transformação do se em si) escreveu admiravelmente a nossa formosíssima língua, a língua luso-brasileira" (SOUSA CORDEIRO, 1898, p. xxiii, grifos do autor).

Mas a questão lingüística haverá de constituir ainda grande ponto de discórdia. É o que se nota em Alberto da Cunha Dias, que, em 1921, desqualifica o autor de Iracema injustamente:

Foi o polemista na imprensa e na tribuna um forte e extrênuo combatente. Ao crítico escasseia uma reta imparcialidade, e sobeja paixão; foi medíocre o dramaturgo e comediógrafo; ressentiu-se o novelista de uma escassa preparação literária e do apressamento precipitado de uma fecunda produção.

$[\ldots]$

Conservador ferrenho em política, levou pirrônico, um mal compreendido patriotismo, encendrado, apaixonado, mas estreito, a salientar virtudes de uma nobreza cavalheiresca nos índios o que, em vez de os exaltar, amesquinha e deforma os seus personagens recortados na vida latejante de exuberância do sertão brasileiro, palpitante de fereza, longe do mundo, em face aos céus inclementes (CUNHA DIAS, 1921, p. 9-10).

Sobre o conceito alencarino da linguagem - a lhe ver no estilo um "propositado mal gosto" (CUNHA DIAS, 1921, p. 12), mostrando estar fortemente vinculado aos puristas do século XIX -, assevera ainda Alberto da Cunha Dias:

A sua prosa que canta a pompa brilhante dos sons nas suas orações, e tem por vezes, nas suas novelas, no abandono das produções, páginas de uma incontestável beleza, e, outras vezes se molda na cadência de um ritmo fácil, é, aqui e além, abruptamente sacudida, cortada por um propósito, pretensioso e inútil, de romper as linhas sóbrias do português castiço (CUNHA DIAS, 1921, p. 12).

Com efeito, não houve dos lusos qualquer estudo sistemático da obra de José de Alencar ao correr do século XX. A bem pouco de seu início, Sampaio Bruno (1900, p. 176) dedica-lhe página na Enciclopédia Portuguesa Ilustrada; terá o nome incluído também no suplemento do Dicionário Popular, de Pinheiro Chagas (Apud SAYERS, 1983, p. 224). 
Excetuando as linhas de Alberto da Cunha Dias, praticamente nada mais se disse da empresa literária alencarina, ainda que fosse "escritor também popularizado no nosso país", conforme salienta Jacinto do Prado Coelho (1981, p. x-xi). Em verdade, ocupar-se-iam dele alguns poucos dicionários, em que vai ser destacado o importante levantamento que faz de nossa vida burguesa e agreste (FRAZÃO e BOAVIDA, 1983, p. 11) - qualidade que lhe nega Jorge de Sena $(1988 \text {, p. 302 })^{3}$-, a sua condição de "criador do romance histórico brasileiro" (CASTRO, 1984, p. 178), ou seu "estilo vigoroso, vivo e musical” (1997, p. 93).

Mas com as iniciativas de Luísa Marinho Antunes (2004) e Antônio das Neves Martins $(2004)^{5}$, inauguram-se, em solo português, os estudos de fundo acerca de sua produção literária. Vêm atestar-lhe a importância não apenas como o "agressivo reformador da língua portuguesa no Brasil" (VIANA FILHO, 1981, p. 318), mas também como quem lhe forneceu a qualidade invulgar para a dimensão nacional e humana da palavra, ontem, hoje, para sempre.

\section{Referências:}

ALENCAR, José de. Pós-Escrito [1870]. In: Iracema. Lenda do Ceará. Rio de Janeiro: José Olympio, 1951, v. VIII. p. 183-205.

ARARIPE JÚNIOR, Tristão de Alencar. José de Alencar: Perfil Literário. In: Obra Crítica de Araripe Júnior. Rio de Janeiro: MEC/Casa de Rui Barbosa, 1958, v. I. p. 130258.

BROCA, Brito. Introdução Biográfica. In: ALENCAR, José de. O Guarani. Romance Brasileiro. 3a ed. Rio de Janeiro: José Olympio, 1955, v. I. p. 19-39.

BRUNO, Sampaio. Alencar. In: LEMOS, Maximiano (Dir.). Enciclopédia Portuguesa Ilustrada. Dicionário Universal. Porto: Lemos \& Cia., 1900, v. I. p. 176.

CASTRO, Aníbal Pinto de. Alencar. In: Lexicoteca. Moderna Enciclopédia Universal. Lisboa: Circulo de Leitores, 1984, t. I. p. 178.

CHAGAS, Pinheiro. José de Alencar. Diário da Manhã, Lisboa, nº 364, 1a página, 20 de setembro de 1876(a).

\footnotetext{
${ }^{3}$ Por contrapartida, Jacinto do Prado Coelho (1966, p. 67) fala da atenção que presta o autor de Iracema ao "condicionalismo local".

${ }^{4}$ Autora de O Romance Histórico e José de Alencar (tese de doutorado defendida em 2004 - Universidade da Madeira).

${ }^{5}$ Autor de José de Alencar: Nova Viseira, Novo Elmo, Outras Guerras (dissertação de mestrado defendida em 2004 - Universidade Clássica de Lisboa).
} 
1876(b).

José de Alencar. Diário da Manhã, Lisboa, no 365, 1a página, 21 de setembro de . Letras e Artes. Anuário do Arquivo Pitoresco, Lisboa, nº 25, p. 198, janeiro de 1866.

Novos Ensaios Críticos. Porto: Viúva Moré - Editora, 1868.

COELHO, Eduardo. Assuntos do Dia. Diário de Notícias, Lisboa, nº 3.807, 1a página, 21 de setembro de 1876(a).

Assuntos do Dia. Diário de Notícias, Lisboa, no 3.841, 1a página, 25 de outubro de 1876(b).

COELHO, Jacinto do Prado. Alencar. In: Dicionário Biográfico Universal de Autores. Lisboa: Artis-Bompiani, 1966, v. I. p. 66-67.

Biografia e Literatura. In: VIANA FILHO, Luís. A Vida de José de Alencar. Porto: Lello \& Irmão - Editores, 1981. p. vii-xi.

CUNHA DIAS, Alberto da. José de Alencar. In: ALENCAR, José de. Ubirajara. Lenda Tupi. Lisboa: Edições Delta, 1921. p. 9-12.

FRANCISCO DA SILVA, Inocêncio. José de Alencar. Arquivo Pitoresco, Lisboa, v. IX, p. 244-246, 1866.

José Martiniano de Alencar. In: ARANHA, Brito (Dir.). Dicionário Bibliográfico Português. 6o do suplemento. Lisboa: Imprensa Nacional, 1885, t. XIII. p. 128-134.

FRAZÃO, Fernanda e BOAVIDA, Maria Filomena. Alencar, José Martiniano de. In: Pequeno Dicionário de Autores de Língua Portuguesa. Lisboa: Amigos do Livro, 1983. p. 11.

Grande Dicionário Enciclopédico Verbo. Lisboa e São Paulo: Editorial Verbo, 1997, v. I. p. 93.

LIMA, Rangel de. Artes e letras, Lisboa, I, p. 95, junho de 1872.

MENESES, Raimundo de. Cartas e Documentos de José de Alencar. São Paulo: Conselho Estadual de Cultura, 1967.

Notícias Diversas. Democracia, Lisboa, nº 869, 1a página, 22 de setembro de 1876.

ORTIGÃO, Ramalho. José de Alencar e Augusto Soromenho. In: As Farpas. Os Indivíduos. Lisboa: David Corazzi - Editor, 1887, t. III. p. 207-221.

PINTO, Silva. No Brasil. Notas de Viagem. Porto: Tipografia de Antônio José da Silva Teixeira, 1879. 
ROMEO JÚNIOR, S. As Letras no Brasil. Duas Palavras Acerca de Um Folheto do Sr. A. de Quental. Braga: Tipografia de Domingos G. Gouvea, 1866.

SAYERS, Raymond. Onze Estudos de Literatura Brasileira. Trad. Roberto Raposo. Rio de Janeiro: Civilização Brasileira; Brasília: INL, 1983.

SENA, Jorge de. Estudos de Cultura e Literatura Brasileira. Lisboa: Edições 70, 1988.

SOUSA CORDEIRO, Antonio Xavier de. José de Alencar. Novo Almanaque de Lembranças Luso-Brasileiro, Lisboa, p. v-xxxii, 1898.

VIANA FILHO, Luís. A Vida de José de Alencar. Porto: Lello \& Irmão - Editores, 1981. 